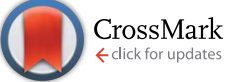

Cite this: RSC Adv., 2015, 5, 37800
Received 23rd January 2015

Accepted 20th April 2015

DOI: 10.1039/c5ra01394a

www.rsc.org/advances

\section{Multi stimuli response of a single surfactant presenting a rich self-assembly behavior $\dagger$}

\author{
M. C. di Gregorio, ${ }^{a}$ M. Varenik, ${ }^{b}$ M. Gubitosi, ${ }^{a}$ L. Travaglini, ${ }^{a}$ N. V. Pavel, ${ }^{a}$ A. Jover, ${ }^{c}$ \\ F. Meijide, ${ }^{c} \mathrm{O}$. Regev ${ }^{\star b}$ and L. Galantini ${ }^{\star a}$
}

This work reports on the multi stimuli sensitivity of a cholic acid derivative in a buffer. The molecules selforganize in single walled tubules at room temperature and $\mathrm{pH}$ 8.0-9.5. By increasing the $\mathrm{pH}$ to 10.0-12.0, these tubules open up and form scrolls, which transform by aging into different tubular structures. A further evolution from scrolls or tubules into ribbons is induced by increasing the temperature. Moreover, a transition into rolled lamellae can be triggered by adding $\mathrm{NaCl}$. All transitions are reversible and accompanied by drastic molecular rearrangements, manifested by spectroscopic and imaging techniques. Such rich multi stimuli responsiveness is usually accomplished by block copolymers or peptides and seldom by pure surfactants. The reported surfactant provides in addition an uncommon variety of structures. The sharpness of the spectroscopic response suggests that the system could be employed in physico-chemical sensors with a rather narrow dynamic range.

\section{Introduction}

Self-assembly stimuli responsive materials are supramolecular structures able to undergo reversible structural transitions of the aggregates in response to one or more external stimuli. This property is widely required in many applications since it offers the possibility to predict, drive and program the behaviour of the aggregates in different environments. ${ }^{1}$ Therefore, the development of such systems has a tremendous potential for application in complex processes such as drug delivery, ${ }^{2-4}$ sensing and biomolecule identification. ${ }^{5}$ Conventional triggers for stimuli sensitive systems are $\mathrm{pH}$, temperature and electrolyte concentration, while more sophisticated approaches are also achieved by exploiting electrical potential, ${ }^{6}$ light, ${ }^{7-10}$ magnetic field, ${ }^{11}$ chemomechanical feedbacks ${ }^{12}$ and enzyme activity. ${ }^{13,14}$ The building blocks of these systems are generally polymers, ${ }^{15}$ peptides ${ }^{16,17}$ and surfactants..$^{18}$

${ }^{a}$ Dipartimento di Chimica, Università di Roma "Sapienza", P. le A. Moro 5, 00185 Roma, Italy. E-mail: luciano.galantini@uniroma1.it

${ }^{b}$ Department of Chemical Engineering, Ben-Gurion University of the Negev, Beer-Sheva 84105, Israel

'Departamento de Quimica Física, Facultad de Ciencias, Universidad de Santiago de Compostela, Avda. Alfonso X El Sabio s/n, 27002 Lugo, Spain

$\dagger$ Electronic supplementary information (ESI) available: Supplementary figures reporting: UV and CD curves of HNaphC solutions as a function of $\mathrm{pH}, \mathrm{UV}$ and CD curves of HNaphC solutions as a function of $\mathrm{NaCl}$ concentration at two different pHs, UV and CD curves of HNaphC solutions proving the reversibility of the $\mathrm{NaCl}$ induced transition, UV and $\mathrm{CD}$ curves of HNaphC solutions as a function of temperature, SLS and DLS measurements on HNaphC solutions as a function of $\mathrm{pH}$ and temperature. Table reporting cryo-TEM image data analysis. See DOI: $10.1039 / \mathrm{c} 5 \mathrm{ra} 01394 \mathrm{a}$
Bile salts are peculiar biological surfactants (Fig. 1). They show an unconventional self-assembly, which cannot be easily rationalized based on common geometric rules for surfactants. ${ }^{19}$ Indeed, due to the presence of a rigid steroidal backbone they present low conformational degrees of freedom and are expected to pack in ordered aggregates.

Their aggregation numbers generally decrease with increasing hydroxylation degrees and can be often tuned by changing parameters such as $\mathrm{pH}$, added electrolyte and temperature, leading to the formation of a variety of aggregate morphologies, e.g., globular or rod-like micelles and tubules..$^{20-24}$ For tubules some interesting stimuli responsive features have been also shown in pure solutions or mixtures. ${ }^{25,26}$ Recently, interest in the synthesis of bile salt derivatives for applicative purposes has risen. For example, cholaphanes and cholapods have been prepared and applied as carbohydrate and anion receptors. ${ }^{27}$ Bile salt-based molecular umbrellas, ${ }^{28}$ linear dendritic copolymers ${ }^{29}$ as well as pegylated, ${ }^{30}$ drug loaded ${ }^{31,32}$ or oxo derivatives ${ }^{33}$ have been used for drug delivery. Amine or ammonium containing bile acid derivatives have shown

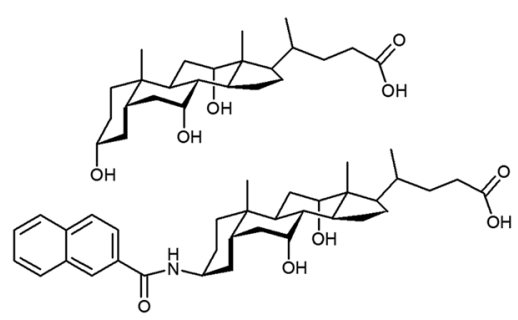

Fig. 1 Molecular structure of the cholic acid (top) and its derivative, HNaphC (bottom). 
antimicrobial activity, ${ }^{\mathbf{3 4}, 35}$ whereas protein stabilizing capability has been demonstrated by sugar-substituted derivatives. ${ }^{36}$ Finally, the introduction of aromatic residues were found to enhance the ability of bile salts to disperse carbon nanotubes. ${ }^{37}$

Bile salt derivatives exhibit different self-assembly behaviours compared to their precursors. ${ }^{38-43}$ They reveal efficient gelation properties ${ }^{\mathbf{4 4 , 4 5}}$ and present appealing stimuli dependent aggregation, especially in derivatives containing hydrophobic residues. ${ }^{\mathbf{4 6 , 4 7}}$ One such derivative, the naphthoilaminesubstituted cholic acid (HNaphC, Fig. 1), is investigated in this work. The study is aimed at exploring the effect of different parameters ( $\mathrm{pH}$, salt concentration, temperature and ageing) on its self-assembly in order to highlight possible multi responsive features. A previous work demonstrated that this molecule forms supramolecular tubules in water, which transform into twisted ribbons upon $\mathrm{pH}$ increase via an unconventional opening mechanism. ${ }^{47}$ Tubular structures are widely used, for example, as nano-containers or to align nanomaterials. The stimuli responsiveness of the tubular system can constitute a significant advantage in applications as it allows a control on their opening-closure and therefore, on inclusion-release of materials. Stimuli multi responsive features enable a reversible and particularly versatile control of these processes.

\section{Results and discussion}

\section{The effect of $\mathrm{pH}$}

The self-assembly of HNaphC was first investigated by recording circular dichroism (CD) and UV spectra in buffered aqueous solutions at different $\mathrm{pH}$ values. The spectra demonstrate relevant structural changes upon $\mathrm{pH}$ variations. The signal evolutions are summarized by molar ellipticity and molar extinction values at representative wavelengths where they show the most significant changes (Fig. 2). In both cases drastic jumps around a transition $\mathrm{pH}$ range of 9-10 are observed. The whole set of spectra are reported in the ESI (Fig. S1 and S2 $\dagger$ ). Scattered light intensity measurements demonstrate that a slight increase of the aggregation number occurs during the transition upon increasing the $\mathrm{pH}$ (Fig. S3†).

A typical UV absorption spectrum of non-aggregated HNaphC (in methanol) presents three main absorptions at around 230, 280 and $330 \mathrm{~nm}$ related to the $\pi-\pi^{*}$ transitions of

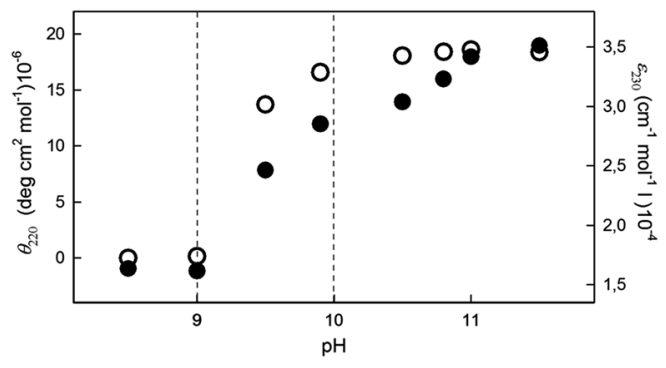

Fig. $2 \mathrm{pH}$ effect: $C D$ and UV measurements: values of the molar ellipticity $[\theta]$ at $220 \mathrm{~nm}$ ( $\theta_{220}$, left axis, black circles) and of the extinction, $\varepsilon$, at $230 \mathrm{~nm}$ ( $\varepsilon_{230}$, right axis, white circles) of a $1.0 \mathrm{mM}$ $\mathrm{HNaphC}$ in carbonate/bicarbonate buffer. the naphthoilamine residue. In bicarbonate buffered aqueous solution $(\mathrm{pH} \approx 8.5)$ the HNaphC aggregation occurs, which induces hypochromic effects on the main peak (Fig. S1a $\dagger$ ). In the same conditions $\mathrm{CD}$ is characterized by a negative band around $215-220 \mathrm{~nm}$ (Fig. S1b †). Increasing the $\mathrm{pH}$ to 9.5 results in a drastic change in both the UV and the CD spectra: increased intensity of the former, and formation of conservative bisignate Cotton effects at 295 and $230 \mathrm{~nm}$ for the latter (Fig. S1c $\dagger$ ). Further $\mathrm{pH}$ increase affects the intensities of the opposite bands of the low wavelength bisignate Cotton effect. The whole behavior suggests that a transition occurs between supramolecular structures at low and high $\mathrm{pH}$ values.

Very similar UV and CD spectrum profiles and evolutions have been reported in a buffer-free system. ${ }^{47}$

Using cryogenic electron transmission microscopy (cryoTEM) we imaged the change in structure and morphology around the transition $\mathrm{pH}$. The vitrification process used in cryoTEM sample preparation allows for direct structural investigation of aggregates in solution without drying or crystallization effects, which may disturb their morphology. Below the transition $\mathrm{pH}(\mathrm{pH}=8.5)$ the micrographs show single wall tubules, $60 \mathrm{~nm}$ in diameter, with a narrow polydispersity (Fig. 3a).

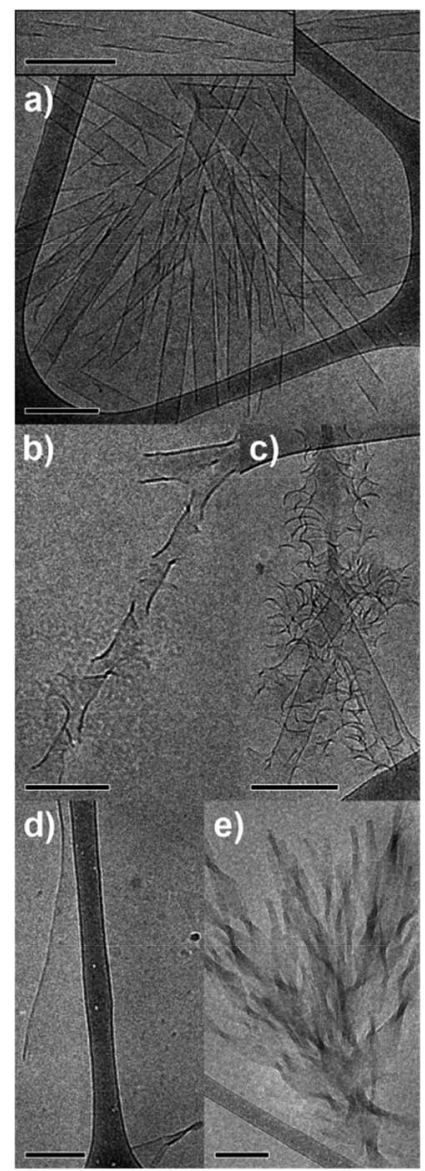

Fig. 3 pH effect: cryo-TEM micrographs of HNaPhC $1.0 \mathrm{mM}$ in buffer at $\mathrm{pH} 8.5$ showing fully (a) and partially (inset (a)) formed tubes, helically-wrapping of ribbons and their opening ( $b$ and $c$ ). At pH 9.6 the micrographs demonstrate flat structures (d) and twisted ribbons (e). $\operatorname{Bar}=200 \mathrm{~nm}$. 
Structures that are not completely formed reveal that tubules are built by helically wrapped ribbons (Fig. 3a, inset). ${ }^{\mathbf{4 8 , 4 9}}$ Above the transition $\mathrm{pH}(\mathrm{pH}=10.6,11.6$ and 12.3) both single wall tubules and scrolls are imaged (Fig. $4 \mathrm{a}-\mathrm{c}$ ), the scroll fraction increasing with $\mathrm{pH}$ (Fig. 4e). Cryo-TEM micrographs of $24 \mathrm{~h}$ aged samples show that a transformation of scrolls into single walled tubules 60-70 in diameter, occurs (Fig. 4d). A sheet merging mechanism of overlapping layers in a scroll has been proposed for such scroll-to single-wall tubule transition. ${ }^{\mathbf{2 4 , 4 3}}$

The samples at the extreme $\mathrm{pH}$ values (8.5 and 12.3) were also characterized by small angle X-ray scattering (SAXS). The scattering curves were fitted to a tubular morphology ${ }^{50}$ (Fig. 5), assuming external and internal diameters of 55 and $59 \mathrm{~nm}$ $(\mathrm{pH}=8.5)$ and 68 and $72 \mathrm{~nm}(\mathrm{pH}=12.3)$, within estimated uncertainties of $\pm 2 \mathrm{~nm}$. These values are in excellent agreement with the diameters obtained by cryo-TEM image analysis (Table $\mathrm{S} 1 \dagger$ ).

Cryo-TEM unambiguously detects a pH-induced single wall tubules-to-scrolls structural transition around the transition $\mathrm{pH}$. Intermediate structures point out that these tubules open up by releasing groups of curved layers similar to leaves (Fig. 3b and c), in agreement with a mechanism previously reported. ${ }^{47}$ Moreover at $\mathrm{pH}=9.6$ we find both twisted ribbons (Fig. 3e) and
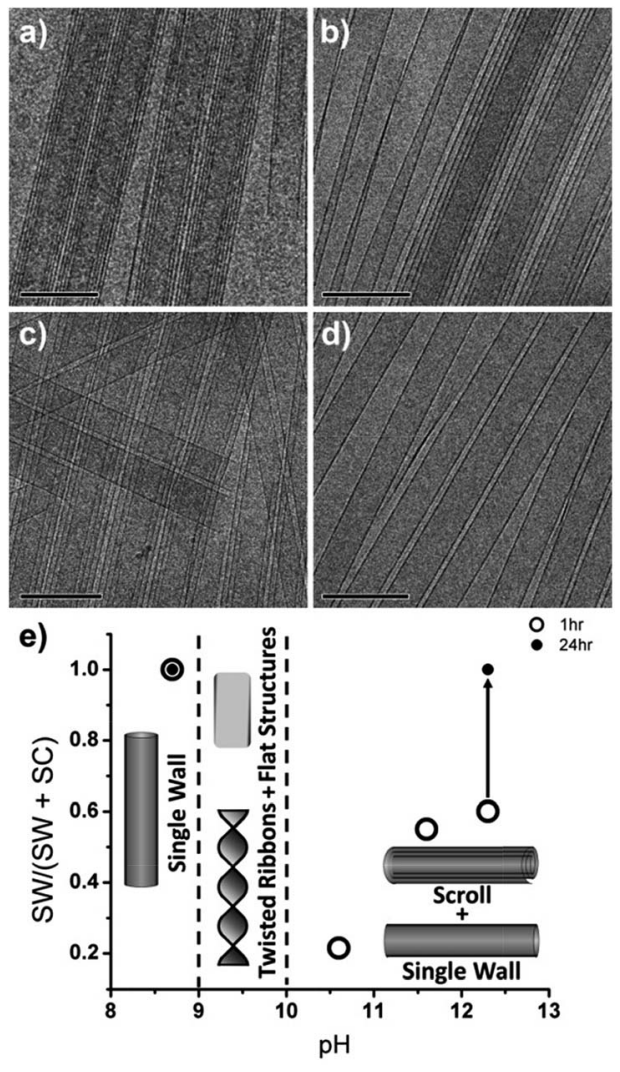

Fig. 4 pH effect: cryo-TEM images of as-prepared HNaphC $1 \mathrm{mM}$ in buffer at $\mathrm{pH}$ values of 10.6 (a), 11.6 (b), 12.3 (c) and $24 \mathrm{~h}$ aged, at $\mathrm{pH} 12.3$ (d). Bar $=200 \mathrm{~nm}$. Schematic report of the tube percentage at different $\mathrm{pH}$ values (abscissa) and time (e). White and black circles represent cryo-TEM image analysis of samples imaged after $1 \mathrm{~h}$ and $24 \mathrm{~h}$ aged, respectively. The ratio single wall tube (SW) number/total number of aggregates, expressed as SW and scrolls (SC), is shown in the ordinate.

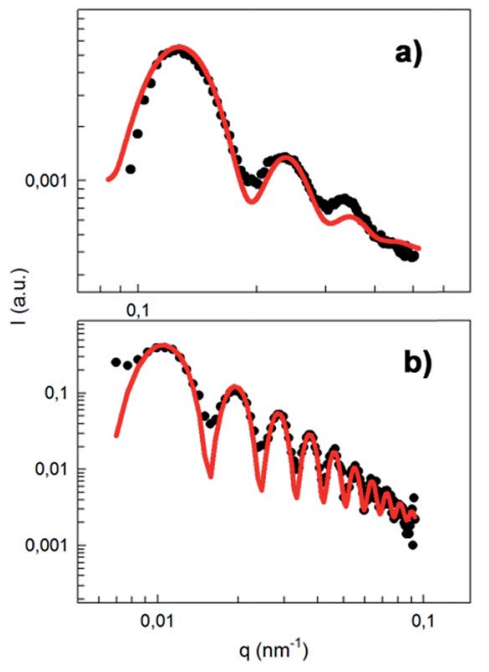

Fig. 5 pH effect: SAXS experimental data (black dots) and form factor fitting to hollow cylinder (red curves) performed on $\mathrm{HNaPhC} 1 \mathrm{mM}$ in carbonate/bicarbonate buffer. Inner and outer diameters are 55 and $59 \mathrm{~nm}$ at $\mathrm{pH} 8.5$ (a) and 78 and $72 \mathrm{~nm}$ at pH 12.3 (b).

thin flat sheets (Fig. 3d, darker regions), which are most probably the building blocks of the scrolls.

We note that the presence of buffer affects the high $\mathrm{pH}$ structure. Indeed, in its absence twisted ribbons are formed, ${ }^{\mathbf{7}}$ rather than scrolls (Fig. 4e).

The peculiar molecular structure of the derivative induces the formation of aggregates with complex interacting geometries, stabilized by a delicate interplay between both geometrically constrained interactions (hydrogens bonds and $\pi-\pi$ stacking $^{51}$ ) and non-directional forces (hydrophobic forces). By decreasing the $\mathrm{pH}$, the protonation of the carboxylic group is expected to trigger the transition by regulating the electrostatic repulsions and the formation of possible hydrogen bonds between the carboxylates. The used buffer likely affects the specific interactions in the selfassembly of the derivative as it determines the formation of scrolls rather than twisted ribbons (formed in its absence) at high $\mathrm{pH}$. The available results do not make it possible to propose a detailed mechanism for these interactions. The kosmotropic features of carbonate could contribute to the buffer effect.

\section{The effect of $\mathrm{NaCl}$ concentration}

The addition of $\mathrm{NaCl}$ to HNaphC samples results in increased turbidity (Fig. 6), suggesting growth of the aggregate size.

The phenomenon is also revealed in UV spectra as an increased background of the entire wavelength range, which extends the chromophore's absorption tail (Figs. S4a and S5a $\dagger$ ). Moreover, a significant decrease in the main UV band intensity and a remarkable change in the CD spectra occur upon $\mathrm{NaCl}$ addition (Fig. S4 and $\mathrm{S} 5 \dagger$ ).

Both the changes in the UV and the CD spectra insinuate the onset of yet another structural transition with salt concentration and its evolution (Fig. 7). 


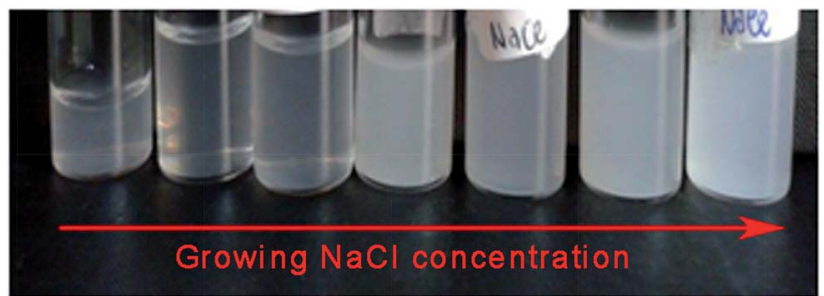

Fig. $6 \mathrm{NaCl}$ effect: solutions of $\mathrm{HNaPhC} 1 \mathrm{mM}$ in buffer at $\mathrm{pH} 8.5$ with $\mathrm{NaCl}$, 3, 5, 10, 20, 40 and $100 \mathrm{mM}$ (from left to right).

Based on the UV profiles, both the turbidity (expressed as molar extinction, $\varepsilon_{\mathrm{T}}$, on the tail of the UV curve at $340 \mathrm{~nm}$ ) and the extinction, $\varepsilon_{\mathrm{A}}$, related to the absorption of the main band $(235 \mathrm{~nm})$ are plotted as a function of $\mathrm{NaCl}$ concentration (Fig. 7a and $b$ ). Both plots suggest that most of the structural transition occurs within the $0-10 \mathrm{mM} \mathrm{NaCl}$ concentration range (roughly 10-30 $\mathrm{mM} \mathrm{Na}^{+}$concentration considering the buffer contributions). A similar pattern is found by following the evolution of the CD ellipticity at representative fixed wavelength of 243 and 219 for the samples at pH 8.5 and 12.3, respectively (Fig. 7c).

In order to verify the reversibility of the salt effect we removed the salt from the aggregates in samples at the highest $\mathrm{NaCl}$ concentrations by centrifugation and we re-dispersed the aggregates in buffer at $\mathrm{pH}=8.5$ and 12.3. The CD measurements of these samples showed the original spectrum before the addition of salt (Fig. S6 $\dagger$ ), proving the reversibility of the salt-induced transformation. It also demonstrates that most of

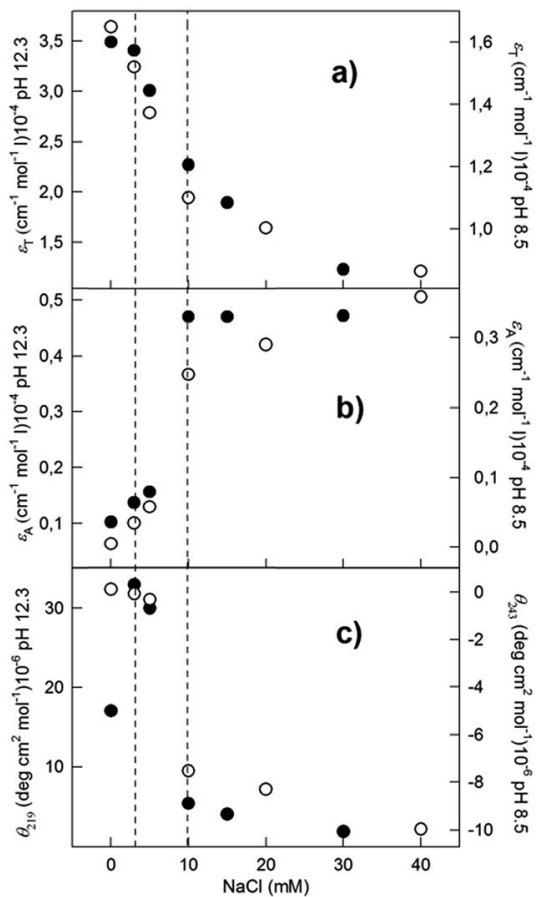

Fig. 7 Salt effect: turbidity, $\varepsilon_{T}$, expressed as $\varepsilon$ at $340 \mathrm{~nm}(\mathrm{a})$, extinction due to absorption at $235 \mathrm{~mm}, \varepsilon_{\mathrm{A}}$, expressed as the difference between $\varepsilon$ at 235 and $\varepsilon_{\top}(\mathrm{b})$, and the molar ellipticity, $[\theta]$, at wavelengths of $243\left(\theta_{243}\right)$ and $219 \mathrm{~nm}\left(\theta_{219}\right)$ (c) for samples in buffer at $\mathrm{pH} 8.5$ (right axis, white circles) and 12.3 (left axis, black circles).
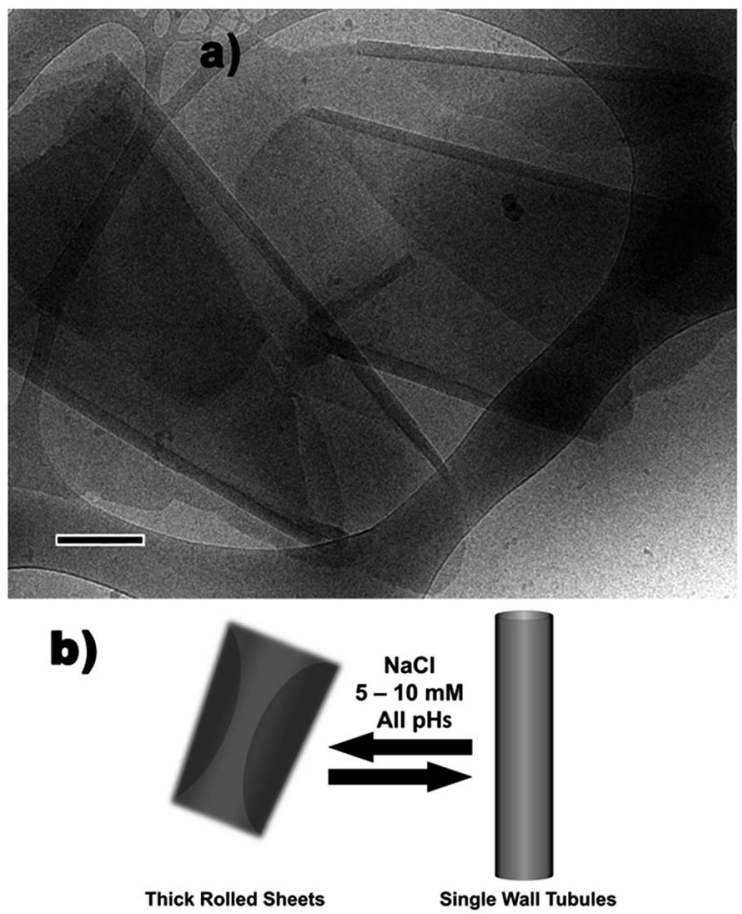

Fig. 8 Salt effect: (a) cryo-TEM images of rolled aggregates in $\mathrm{HNaphC} 1 \mathrm{mM}$ in buffer in the presence of $\mathrm{NaCl} 20 \mathrm{mM}$ at $\mathrm{pH}=12.0$, bar $=200 \mathrm{~nm}$; (b) scheme of the salt induced transition.

the added $\mathrm{NaCl}$ is not included in the aggregates and it is eliminated with the supernatant. Cryo-TEM micrographs of HNaphC samples in $20 \mathrm{mM} \mathrm{NaCl}$ show the presence of lamellae, often edge-rolled, and forming truncated cones, $\sim 0.5 \mu \mathrm{m}$ in diameter at the transversal section (Fig. 8).

We believe that the added salt screens the electrostatic repulsions between the charged head groups, leading to the structural transition. Kosmotropic effects of the added salts could also influence the transition.

\section{The effect of temperature}

Samples heated to $55{ }^{\circ} \mathrm{C}(\mathrm{pH}=12.3)$ show a transition from tubule (Fig. 5c) to ribbon-like structures (Fig. 9).

The temperature effect is also manifested by measuring the molar ellipticity and the extinction coefficient at 233 and $220 \mathrm{~nm}$, respectively (Fig. 10). Both these parameters present a step change at $35-40{ }^{\circ} \mathrm{C}$.

In detail, the UV spectra of $1.0 \mathrm{mM} \mathrm{HNaPhC}$ at $\mathrm{pH} 12.3$ remain unchanged up to $30{ }^{\circ} \mathrm{C}$, whereas further temperature increase produces a remarkable intensity drop in the $200-300 \mathrm{~nm}$ range, which is completed above $40{ }^{\circ} \mathrm{C}$ (Fig. S7a†). Accordingly, the CD spectra do not significantly changes up to $30^{\circ} \mathrm{C}$ (Fig. S7b $\dagger$ ), above which it drastically drops. Cooling the sample back to $25^{\circ} \mathrm{C}$, both UV and CD original curves reappear, demonstrating the reversibility of the transformation and the possibility to toggle between the two different molecular packings.

The transition is also detected by differential scanning calorimetry (DSC), which shows a broad endothermic peak in the $40-50{ }^{\circ} \mathrm{C}$ range (Fig. 10 inset). 


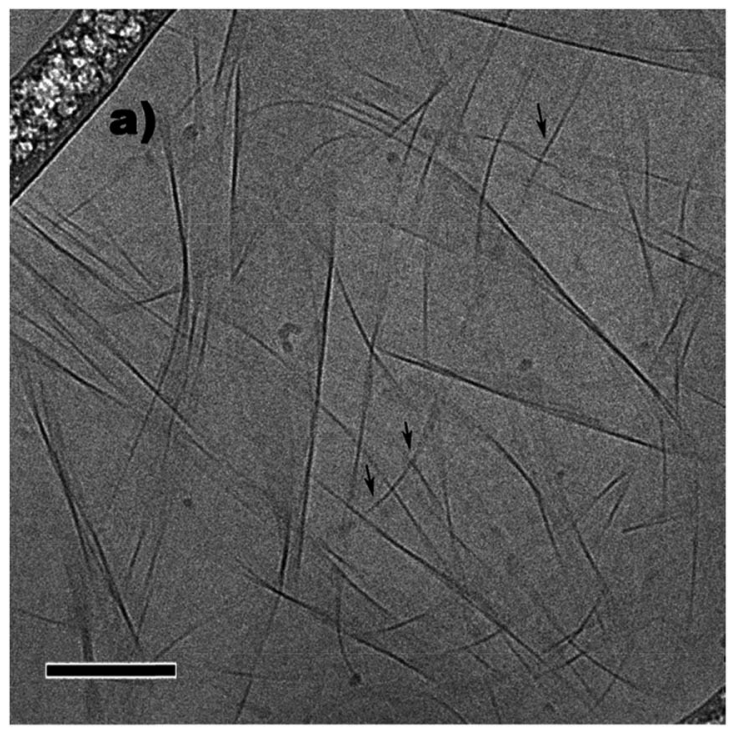

b)

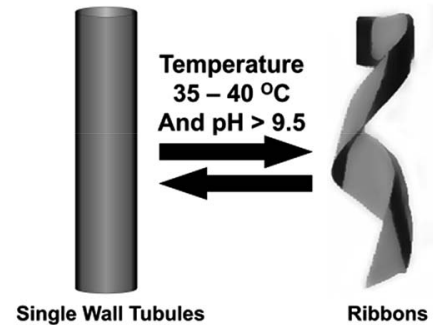

Fig. 9 Temperature effect: (a) cryo-TEM micrographs of ribbons in $1 \mathrm{mM} \mathrm{HNaphC}$ in buffer at $55^{\circ} \mathrm{C}(\mathrm{pH}$ 12.3), arrows indicate twists in a narrow ribbon, bar $=200 \mathrm{~nm}$; (b) scheme of the temperature induced transition.

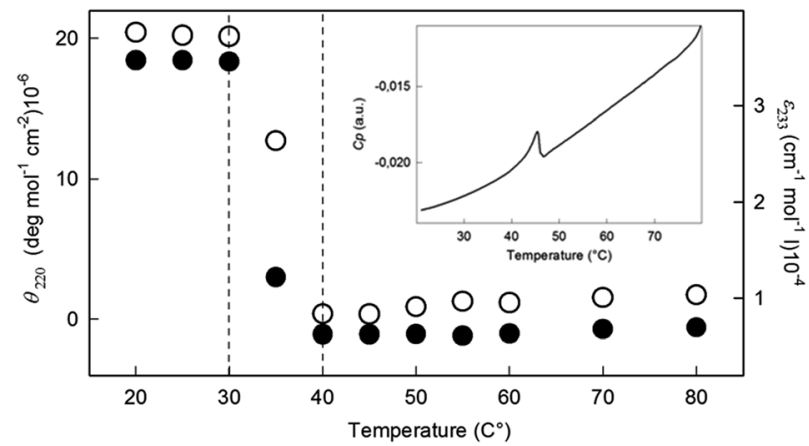

Fig. 10 Temperature effect: molar ellipticity at $223 \mathrm{~nm}, \theta_{223}$ (left axis, black circles), and molar extinction at $233 \mathrm{~nm}, \varepsilon_{233}$ (right axis, white circles), in $1 \mathrm{mM} \mathrm{HNaphC}$ in buffer. The up-scan DSC thermogram is reported in the inset.

Static and dynamic light scattering (SLS and DLS) measurements at increasing temperature also confirm the transition, showing a decrease in the scattered light intensities and hydrodynamic radii, starting from the transition temperature (Fig. S8†).

Within the complex framework of intermolecular interactions provided by HNaphC, thermal response could be due to an increase in the strength of hydrophobic interactions during heating that involves both the naphthoilamine residue and the hydrophobic face of the rigid group.

\section{Experimental}

\section{Materials}

HNaphC was obtained by reacting the 2-naphthoyl chloride with the $3 \beta$-amino derivative of cholic acid. Details on the synthesis were reported elsewhere. ${ }^{47}$

Solutions of HNaphC were prepared by solubilizing the powder in aqueous solvents. Starting from a sample containing sodium or potassium bicarbonate $10 \mathrm{mM}$ (initial $\mathrm{pH}=8.5$ ), the $\mathrm{pH}$ value was progressively increased by adding sodium or potassium hydroxide up to a $\mathrm{pH}$ of 12.3. Samples with $\mathrm{NaCl}$ (Carlo Erba) ranging from $5 \mathrm{mM}$ to $100 \mathrm{mM}$ are also prepared to study the electrolyte concentration effect on the self-assembly.

In order to test the reversibility of the transition with electrolyte concentration, centrifugation on samples both at $\mathrm{pH} 8.5$ and 11.5 with $\mathrm{NaCl} 100 \mathrm{mM}$ was performed at $5000 \mathrm{rpm}$ for 5 minutes. After removing the supernatant, the precipitate was re-dispersed in buffer solution at the same initial $\mathrm{pH}$, obtaining homogenous solutions.

\section{CD and UV measurements}

The UV absorbance spectra were recorded on a Cary/1E spectrophotometer and reported in molar extinction coefficient $\varepsilon$. CD spectra were recorded on a JASCO model 715 and reported in molar ellipticity $\theta$. The spectra were recorded in the range of wavelength $(\lambda)$ 200-350 $\mathrm{nm}$ and the temperature was controlled by a Peltier unit, with an accuracy of $0.02{ }^{\circ} \mathrm{C}$. Quartz cuvettes with path lengths ranging from 0.1 to $1 \mathrm{~mm}$ were employed, depending on the signal intensity. The reported spectra are results of four scans and solvent baseline correction.

\section{SAXS measurements}

SAXS measurements were performed on a Ganesha SAXS system. The instrument has a Pilatus detector and a Genix 3D $\mathrm{X}$-ray source and it uses a X-ray wavelength, $\lambda$, of $1.54 \AA$. All the scattering curves, recorded within the range of $0.01<q<0.4 \AA^{-1}$ ( $q=4 \pi \sin (\theta) / \lambda$, where $2 \theta$ is the scattering angle), were corrected for solvent and capillary contributions.

For very long tubular scattering particles, the SAXS spectra can be interpreted on the basis of the following theoretical expression of the intensity for infinitely long hollow cylinder: ${ }^{50}$

$$
I(q) \propto\left\langle\left[D_{\mathrm{o}}{ }^{2} \frac{J_{1}\left(q D_{\mathrm{o}} / 2\right)}{q D_{\mathrm{o}} / 2}-D_{\mathrm{i}}{ }^{2} \frac{J_{1}\left(q D_{\mathrm{i}} / 2\right)}{q D_{\mathrm{i}} / 2}\right]^{2}\right\rangle
$$

where $D_{\mathrm{o}}$ and $D_{\mathrm{i}}$ are the outer and inner diameters of the tube, respectively, and $J_{n}(x)$ is the $n$ order Bessel function of the first kind. The average in this equation is considered with respect to a distribution of diameters. In our calculations a Gaussian distribution with a $10 \%$ standard deviation was considered. In the fit we observed that the calculated scattering curves with this polydispersity show deeper minima than the experimental data, and that a larger polydispersity allowed for a better fit. However, larger percentages were not used because a partial 
smearing of the experimental form factor minima is expected to be due to other effects, such as a continuous rather than discontinuous cross section profile of the electron density, as considered in the fit equation.

\section{Cryo-TEM measurements}

Cryo-TEM images were collected using a FEI Tecnai 12 G2 (equipped with a Gatan 794 CCD camera) operating at $120 \mathrm{kV}$. The samples were prepared using a controlled environment vitrification system. A drop of the sample was deposited on a $\mathrm{Cu}$ TEM grid, coated with a holey carbon film (Lacey substrate 300 mesh, Ted Pella, Ltd.) at $25{ }^{\circ} \mathrm{C}$. The grid was blotted to remove excess fluid, resulting in a thin film $(20-300 \mathrm{~nm})$ of the solution suspended over the grid's holes. The samples were vitrified by rapid plunging into liquid ethane at its freezing point, then transferred to a cryo holder (Gatan model 626) and examined at $-178{ }^{\circ} \mathrm{C}$.

\section{SLS and DLS measurements}

A Brookhaven instrument constituted by a BI-2030AT digital correlator with 136 channels and a BI-200SM goniometer was used for static and dynamic light scattering (SLS and DLS, respectively). The light source was a Uniphase solid-state laser system model 4601 operating at $532 \mathrm{~nm}$. The temperature was controlled within $0.5{ }^{\circ} \mathrm{C}$ by a circulating water bath. The data were collected at a fixed angle of $90^{\circ}$.

\section{DSC measurements}

DSC measurements were carried out using a VP-DSC differential scanning calorimeter (MicroCal, Northampton, MA.). Approximately $0.5 \mathrm{~mL}$ of sample and water (as standard sample) were injected to the sample and reference cells (made from tantalum alloy), respectively. The sample was equilibrated for $20 \mathrm{~min}$ at $20{ }^{\circ} \mathrm{C}$ before starting the measurements. Two up-scan measurements in the range of $20-80{ }^{\circ} \mathrm{C}$ with scan rate of $60{ }^{\circ} \mathrm{C} \mathrm{h}^{-1}$ were carried out. After the first up-scan the temperature was decreased to $20^{\circ} \mathrm{C}$ and it was equilibrated for $120 \mathrm{~min}$ before starting the second up-scan. Both first and second upscans gave similar thermograms. To collect and analyze DSC data, Origin software supplied by the manufacturer was used.

\section{Conclusions}

We report a multi stimuli responsiveness of a cholic acid derivative to $\mathrm{pH}$, salt concentration, temperature and ageing. Manipulating these external stimuli dictates different selfassembled structures: SW tubules, scrolls, ribbons or rolled lamellae. The transitions between these structures are reversible and entail chromophore rearrangement. The multi stimuli responsiveness of the tubular system offers advantages in applications, allowing versatile opening-closure manipulation in inclusion-release of materials.

Such rich and varied multi (four) stimuli responsiveness is sometimes provided by block copolymers, ${ }^{52-55}$ peptide chains ${ }^{56}$ or surfactant based mixtures, ${ }^{57-60}$ but it is uncommon for a single surfactant system. The few cases of pure surfactant systems reported in the literature ${ }^{\mathbf{4 , 6 1 , 6 2}}$ involve the formation of different and generally less ordered aggregates, like micelles or gels. Finally, the structural transitions take place within a rather narrow range of the triggering stimulus: $1 \mathrm{pH}$ unit, few kelvins, and $10 \mathrm{mM}$ of salt concentration, demonstrating a significant change in UV and CD. Therefore, this system could be employed in physico-chemical sensors with a rather narrow dynamic range.

\section{Acknowledgements}

We thank Prof. Karin Schillén for valuable discussion and collection of DSC data. ESMI Project is acknowledged for financial support (E131100452).

\section{Notes and references}

1 R. Yerushalmi, A. Scherz, M. E. v. d. Boom and H.-B. Kraatz, J. Mater. Chem., 2005, 15, 4480-4487.

2 S. Mura, J. Nicolas and P. Couvreur, Nat. Mater., 2013, 12, 991-1003.

3 X.-Y. Hu, K. Jia, Y. Cao, Y. Li, S. Qin, F. Zhou, C. Lin, D. Zhang and L. Wang, Chem.-Eur. J., 2015, 21, 1208-1220.

4 L. Milanesi, C. A. Hunter, N. Tzokova, J. P. Waltho and S. Tomas, Chem.-Eur. J., 2011, 17, 9753-9761.

5 C. L. Yeung, P. Iqbal, M. Allan, M. Lashkor, J. A. Preece and P. M. Mendes, Adv. Funct. Mater., 2010, 20, 2657-2663.

6 H. Kim, S.-M. Jeong and J.-W. Park, J. Am. Chem. Soc., 2011, 133, 5206-5209.

7 J.-F. Gohy and Y. Zhao, Chem. Soc. Rev., 2013, 42, 7117-7129.

8 Q. Yan, Y. Xin, R. Zhou and Y. Yina, Chem. Commun., 2011, 47, 9594-9596.

9 S. Halmy, F. A. Leibfarth, S. Oh, J. E. Poelma, C. J. Hawker and J. R. de Alaniz, J. Am. Chem. Soc., 2014, 136, 8169-8172.

10 Q. Qi, J. Qian, S. Ma, B. Xu, S. X.-A. Zhang and W. Tian, Chem.-Eur. J., 2015, 21, 1149-1155.

11 J. Thévenot, H. Oliveira, O. Sandre and S. Lecommandoux, Chem. Soc. Rev., 2013, 42, 7099-7116.

12 A. Grinthal and J. Aizenberg, Chem. Soc. Rev., 2013, 42, 70727085.

13 A. J. Harnoy, I. Rosenbaum, E. Tirosh, Y. Ebenstein, R. Shaharabani, R. Beck and R. J. Amir, J. Am. Chem. Soc., 2014, 136, 7531-7534.

14 R. J. Williams, A. M. Smith, R. Collins, N. Hodson, A. K. Das and R. V. Ulijn, Nat. Nanotechnol., 2009, 4, 19-24.

15 M. A. C. Stuart, W. T. S. Huck, J. Genzer, M. Müller, C. Ober, M. Stamm, G. B. Sukhorukov, I. Szleifer, V. V. Tsukruk, M. Urban, F. Winnik, S. Zauscher, I. luzinov and S. Minko, Nat. Mater., 2010, 9, 101-113.

16 D. W. P. M. Löwik, E. H. P. Leunissen, M. van den Heuvel, M. B. Hansen and J. C. M. van Hest, Chem. Soc. Rev., 2010, 39, 3394-3412.

17 E. G. Bellomo, M. D. Wyrsta, L. Pakstis, D. J. Pochan and T. J. Deming, Nat. Mater., 2004, 3, 244-248.

18 P. Brown, C. P. Butts and J. Eastoe, Soft Matter, 2013, 9, 23652374. 
19 J. N. Israelachvili, D. J. Mitchell and B. V. Ninham, J. Chem. Soc., Faraday Trans. 2, 1979, 72, 1525-1568.

20 D. Madenci and S. U. Egelhaaf, Curr. Opin. Colloid Interface Sci., 2010, 15, 109-115.

21 C. Leggio, L. Galantini, E. Zaccarelli and N. V. Pavel, J. Phys. Chem. B, 2005, 109, 23857-23869.

22 A. A. D'Archivio, L. Galantini and E. Tettamanti, J. Phys. Chem. B, 2000, 104, 9255-9259.

23 L. Galantini, E. Giglio, A. Leonelli and N. V. Pavel, J. Phys. Chem. B, 2004, 108, 3078-3085.

24 P. Terech, A. De Geyer and A. Y. Talmon, Adv. Mater., 2002, 14, 495-498.

25 X. Zhang, J. Zou, K. Tamhane, F. F. Kobzeff and J. Fang, Small, 2010, 6, 217-220.

26 X. Zhang, T. Bera, W. Liang and J. Fang, J. Phys. Chem. B, 2011, 115, 14445-14449.

27 P. R. Brotherhood and A. P. Davis, Chem. Soc. Rev., 2010, 39, 3633-3647.

28 V. Janout and S. L. Regen, Bioconjugate Chem., 2009, 20, 183192.

29 J. Luo, K. Xiao, Y. Li, J. S. Lee, L. Shi, Y.-H. Tan, L. Xing, R. H. Cheng, G.-Y. Liu and K. S. Lam, Bioconjugate Chem., 2010, 21, 1216-1224.

30 F. Le Dévédec, D. Fuentealba, S. Strandman, C. Bohne and X. X. Zhu, Langmuir, 2012, 28, 13431-13440.

31 S. Patil, S. Patil, S. Gawali, S. Shende, S. Jadhav and S. Basu, RSC Adv., 2013, 3, 19760-19764.

32 K. Margulis-Goshen, M. C. di Gregorio, N. V. Pavel, L. Abezgauz, D. Danino, J. Vázquez Tato, V. H. Soto Tellini, S. Magdassi and L. Galantini, Phys. Chem. Chem. Phys., 2013, 15, 6016-6024.

33 L. Yang, H. Zhang, M. Mikov and I. G. Tucker, Mol. Pharmaceutics, 2009, 6, 448-456.

34 H. M. Willemen, L. C. P. M. de Smet, A. Koudijs, M. C. A. Stuart, I. G. A. M. Heikamp-de Jong, A. T. M. Marcelis and E. J. R. Sudholter, Angew. Chem., Int. Ed., 2002, 41, 4275-4277.

35 C. Li, A. S. Peters, E. L. Meredith, G. W. Allman and P. B. Savage, J. Am. Chem. Soc., 1998, 120, 2961-2962.

36 Q. Zhang, X. Ma, A. Ward, W.-X. Hong, V.-P. Jaakola, R. C. Stevens, M. G. Finn and G. Chang, Angew. Chem., Int. Ed., 2007, 46, 7023-7025.

37 M. Gubitosi, J. V. Trillo, A. Alfaro Vargas, N. V. Pavel, D. Gazzoli, S. Sennato, A. Jover, F. Meijide and L. Galantini, J. Phys. Chem. B, 2014, 118, 1012-1021.

38 L. Travaglini, A. D'Annibale, K. Schillén, U. Olsson, S. Sennato, N. V. Pavel and L. Galantini, Chem. Commun., 2012, 48, 12011-12013.

39 L. Travaglini, M. Gubitosi, M. C. di Gregorio, N. V. Pavel, A. D'Annibale, M. Giustini, V. H. Soto Tellini, J. Vázquez Tato, M. Obiols-Rabasa, S. Bayati and L. Galantini, Phys. Chem. Chem. Phys., 2014, 16, 19492-19504.

40 F. Meijide, J. V. Trillo, S. de Frutos, L. Galantini, N. V. Pavel, V. H. Soto, A. Jover and J. Vázquez Tato, Steroids, 2012, 77, 1205-1211.
41 J. V. Trillo, F. Meijide, A. Jover, V. H. Soto, S. de Frutos, M. C. di Gregorio, L. Galantini and J. Vázquez Tato, $R S C$ Adv., 2014, 4, 5598-5606.

42 L. Travaglini, A. D'Annibale, M. C. di Gregorio, K. Schillen, U. Olsson, S. Sennato, N. V. Pavel and L. Galantini, J. Phys. Chem. B, 2013, 117, 9248-9257.

43 M. Gubitosi, L. Travaglini, A. D'Annibale, K. Schillén, U. Olsson, N. V. Pavel, J. Vázquez Tato, M. Obiols-Rabasa, S. Sennato and L. Galantini, Langmuir, 2014, 30, 6358-6366. 44 M. C. di Gregorio, N. V. Pavel, J. Miragaya, A. Jover, F. Meijide, J. Vázquez Tato, V. H. Soto Tellini and L. Galantini, Langmuir, 2013, 29, 12342-12351.

45 P. Terech, S. Dourdain, U. Maitra and S. Bhat, J. Phys. Chem. $B, 2009,113,4619-4630$.

46 L. Galantini, C. Leggio, A. Jover, F. Meijide, N. V. Pavel, V. H. Soto Tellini, J. Vázquez Tato, R. Di Leonardo and G. Ruocco, Soft Matter, 2009, 5, 3018-3025.

47 M. C. di Gregorio, N. V. Pavel, A. Jover, F. Meijide, J. Vázquez Tato, V. H. Soto Tellini, A. Alfaro Vargas, O. Regev, Y. Kasavi, K. Schillén and L. Galantini, Phys. Chem. Chem. Phys., 2013, 15, 7560-7566.

48 L. Ziserman, H.-Y. Lee, S. R. Raghavan, A. Mor and D. Danino, J. Am. Chem. Soc., 2011, 133, 2511-2517.

49 T. Shimizu, M. Masuda and H. Minamikawa, Chem. Rev., 2005, 105, 1401-1444.

50 C. V. Teixeira, H. Amenitsch, T. Fukushima, J. P. Hill, W. Jin, T. Aida, M. Hotokka and M. Linden, J. Appl. Cryst., 2010, 43, 850-857.

51 E. Gazit, FASEB J., 2002, 16, 77-83.

52 A. Klaikherd, C. Nagamani and S. Thayumanavan, J. Am. Chem. Soc., 2009, 131, 4830-4838.

53 J. Dong, Y. Wang, J. Zhang, X. Zhan, S. Zhu, H. Yang and G. Wang, Soft Matter, 2013, 9, 370-373.

54 E. Krieg, E. Shirman, H. Weissman, E. Shimoni, S. G. Wolf, I. Pinkas and B. Rybtchinski, J. Am. Chem. Soc., 2009, 131, 14365-14373.

55 J. Zhuang, M. R. Gordon, J. Ventura, L. Li and S. Thayumanavan, Chem. Soc. Rev., 2013, 42, 7421-7435.

56 P. Fatás, J. Bachl, S. Oehm, A. I. Jiménez, C. Cativiela and D. D. Díaz, Chem.-Eur. J., 2013, 19, 8861-8874.

57 C. B. Minkenberg, L. Florusse, R. Eelkema, G. J. M. Koper and J. H. van Esch, J. Am. Chem. Soc., 2009, 131, 1127411275.

58 L. Jiang, K. Wang, F. Ke, D. Liang and J. Huang, Soft Matter, 2009, 5, 599-606.

59 W. Miao, L. Qin, D. Yang, X. Jin and M. Liu, Chem.-Eur. J., 2015, 21, 1064-1072.

60 J. Zhao, Y.-M. Zhang, H.-L. Sun, X.-Y. Chang and Y. Liu, Chem.-Eur. J., 2014, 20, 15108-15115.

61 X. Li, Y. Yang, J. Eastoe and J. Dong, ChemPhysChem, 2010, 11, 3074-3077.

62 F. Wang, A. Klaikherd and S. Thayumanavan, J. Am. Chem. Soc., 2011, 133, 13496-13503. 